This item was submitted to Loughborough's Research Repository by the author.

Items in Figshare are protected by copyright, with all rights reserved, unless otherwise indicated.

\title{
ELASTIC - a methodological framework for identifying and selecting sustainable transport indicators
}

PLEASE CITE THE PUBLISHED VERSION

http://www.sciencedirect.com/science/article/pii/S1361920909001102

\section{PUBLISHER}

(C) Elsevier

VERSION

AM (Accepted Manuscript)

LICENCE

CC BY-NC-ND 4.0

\section{REPOSITORY RECORD}

Castillo, Nicodemus Herb, and D.E. Pitfield. 2019. "ELASTIC - a Methodological Framework for Identifying and Selecting Sustainable Transport Indicators". figshare. https://hdl.handle.net/2134/8973. 
This item was submitted to Loughborough's Institutional Repository (https://dspace.lboro.ac.uk/) by the author and is made available under the following Creative Commons Licence conditions.

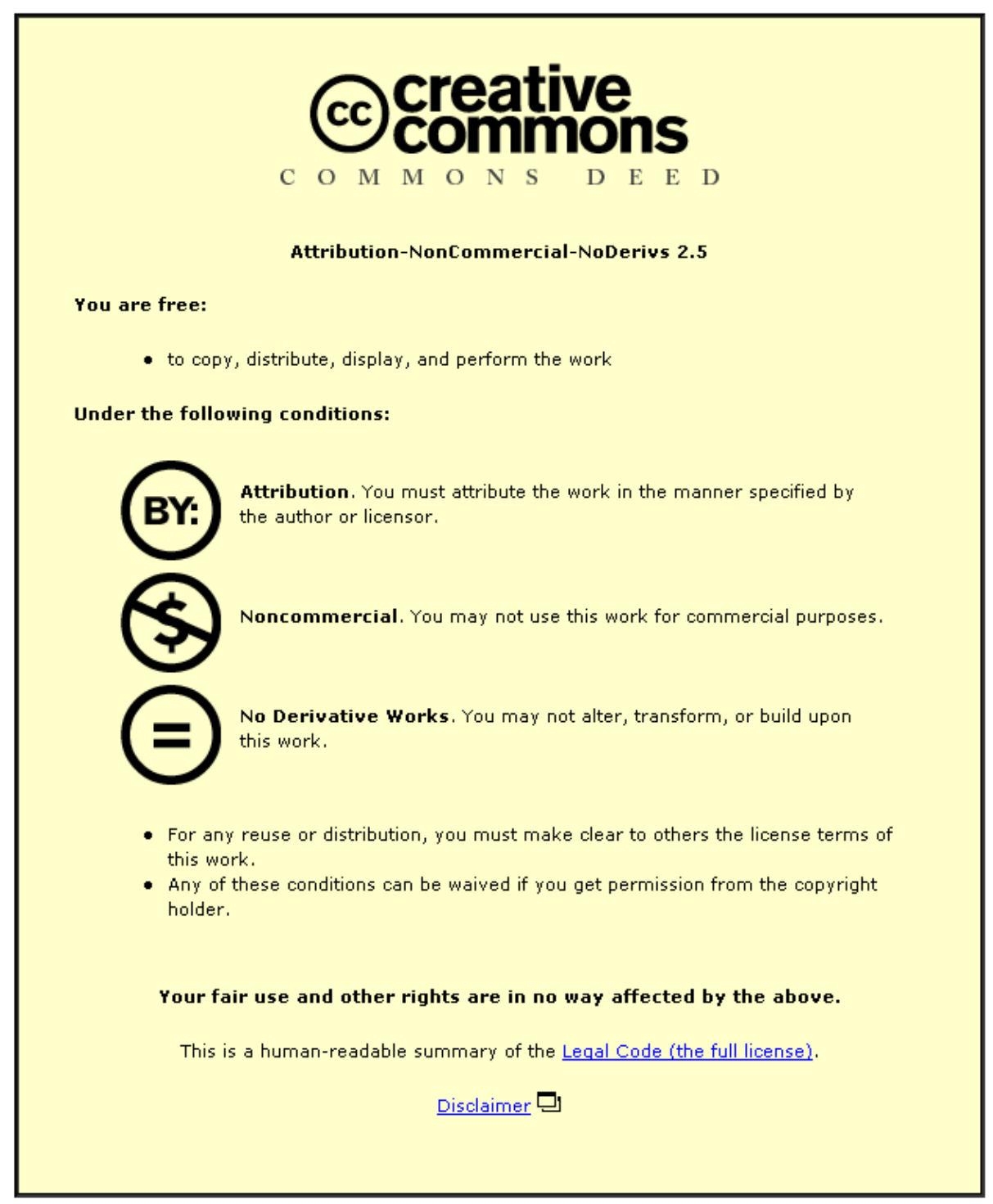

For the full text of this licence, please go to: http://creativecommons.org/licenses/by-nc-nd/2.5/ 


\title{
ELASTIC - a methodological framework for indentifying and selecting sustainable transport indicators
}

\author{
Herb Castillo* \\ Sustainability and Management Research Group \\ Queen's University Management School \\ Queen's University Belfast \\ 25 University Square \\ Belfast, Co. Antrim \\ BT7 1NN, United Kingdom \\ David E. Pitfield \\ Transport Studies Group \\ Department of Civil and Building Engineering \\ Loughborough University \\ Loughborough \\ Leicestershire, LE11 3TU \\ United Kingdom
}

\begin{abstract}
As a consequence of their ability to reflect multiple issues, there is now significant reliance on sustainable transport indicators for monitoring and reporting progress towards sustainable transport. However, the selection of appropriate sustainable transport indicators presents a number of challenges, not least because of the vast number of potential indicators available. To help address these challenges, this paper presents the Evvaluative and Logical Approach to Sustainable Iransport Indicator Compilation (ELASTIC) - a framework for identifying and selecting a small subset of sustainable transport indicators. ELASTIC is demonstrated with an application to the English Regions, UK, which provides valuable insight into the challenge of meeting all the various requirements of sustainable transport in a single indicator set.
\end{abstract}

Key Words: sustainable transport indicators; sustainability assessment; multi-criteria decision analysis; analytic hierarchy process; participatory transport planning

\footnotetext{
* Corresponding author. Address: Queen's University Management School, 25 University Square, Queen's University Belfast, Belfast BT7 1NN, United Kingdom. Tel.: +44(0)2890 973835; Fax: +44(0) 289097 5156. E-mail address: herb.castillo@qub.ac.uk
} 


\section{Introduction}

Sustainable transport has become the fundamental goal of transport policy in many countries (see for example, DETR 1998; New Zealand Ministry of Transport 2008). As with any goal, decision-makers therefore now have to monitor and regularly report system performance in order to manage progress towards sustainable transport.

Sustainable transport indicators are proving to be popular tools for this purpose. The attractiveness of indicators in this context is largely due to their ability to provide informative signals on the multiplicity of issues inherent in considerations of sustainability.

Given the popularity of indicator-based sustainable transport assessment, systematic approaches for selecting appropriate sustainable transport indicators could support the transport planning and assessment process. Towards that end, this paper presents the Evvaluative and Logical Approach to Sustainable Iransport Indicator Compilation (ELASTIC). In summary, ELASTIC provides a framework for identifying a suite of indicators based on stakeholder judgements of their analytical soundness and relevance to key objectives of sustainable transport.

The remainder of this paper is structured as follows. Section 2 introduces the concept of sustainable transport. Section 3 describes the attractiveness of indicators as tools for assessing sustainable transport. Section 4 presents the ELASTIC framework, and section 5 builds on this by describing the application of ELASTIC to the English transport system. Section 6 presents the results of the application, whilst Section 7 concludes the paper by outlining the key findings of the study.

\section{The concept of sustainable transport}

At the highest level, sustainable transport can be viewed as the expression of sustainable development in the transport sector. Whilst a number of definitions have been suggested (see for example Black 1996, European Commission Joint Expert Group on Transport and Environment 2000), there is currently no single universally accepted definition of 'sustainable transport'. 
Given the absence of a single definition, a popular approach in practice and literature is to frame the concept is-by proposing principles and desirable attributes of a sustainable transport system.

The PROSPECTS project (May et al 2001) for example, identified five overarching objectives for sustainable transport, namely:

i. Livable streets and neighbourhoods

ii. Protection of the environment

iii. Equity and social inclusion

iv. Health and Safety

v. Support of a vibrant \& efficient economy

Review of the academic literature and a number of policy documents found that the principles and desirable attributes commonly suggested for sustainable transport, fit well into the overarching objectives for sustainable transport proposed by the PROSPECTS Project. This is illustrated in Table 1 below.

Given this demonstrable, the five overarching-objectives proposed by the PROSPECTS project are viewed in this study as being useful overarching objectives for sustainable transport. 


\begin{tabular}{|c|c|c|c|c|c|}
\hline \multirow[b]{2}{*}{ Source } & \multicolumn{5}{|c|}{ PROSPECTS objectives and attributes commonly proposed in literature and practice } \\
\hline & $\begin{array}{l}\text { Livable Streets \& } \\
\text { Neighbourhood }\end{array}$ & Protection of the Environment & Equity and Social Inclusion & Health \& Safety & $\begin{array}{l}\text { Support of a vibrant } \\
\& \text { efficient economy }\end{array}$ \\
\hline $\begin{array}{l}\text { Gilbert and } \\
\text { Tanguay } \\
\text { (2000) }\end{array}$ & Minimises noise & $\begin{array}{l}\text { - Limits waste within the planet's } \\
\text { ability to absorb them } \\
-\quad \text { Minimises consumption of non- } \\
\text { renewable resources } \\
-\quad \text { Reuses and recycles } \\
\text { components } \\
-\quad \text { Minimises use of land } \\
-\quad \text { Maintains ecosystem health }\end{array}$ & \begin{tabular}{|l} 
- Meets basic needs of \\
individuals and society \\
Consistent with human \\
health \\
Ensures that access is met \\
equitably \\
Operates efficiently \\
- Offers a choice of transport \\
modes
\end{tabular} & $\begin{array}{r}\text { Ensures that } \\
\text { mobility needs } \\
\text { are met safely }\end{array}$ & $\begin{array}{l}\text { - Supports a vibrant } \\
\text { Economy }\end{array}$ \\
\hline OECD (1997) & $\begin{array}{l}\text { Integrates land } \\
\text { use and transport } \\
\text { planning }\end{array}$ & $\begin{array}{l}\text { - Prevents pollution } \\
\text { - Minimises land and resource use }\end{array}$ & \begin{tabular}{|l} 
Provides access to key \\
services \\
- Contributes to equity \\
$-\quad$ Facilitates education and \\
public participation
\end{tabular} & $\begin{array}{l}\text { Maximises } \\
\text { health and } \\
\text { safety }\end{array}$ & $\begin{array}{l}\text { - Supports economic } \\
\text { well-being and } \\
\text { viability }\end{array}$ \\
\hline $\begin{array}{l}\text { Shiftan et al } \\
\text { (2003) }\end{array}$ & & $\begin{array}{l}\text { - Reduces energy consumption } \\
\text { - Minimise air pollution from road } \\
\text { transport } \\
\text { - Protects wildlife and natural } \\
\text { habitats }\end{array}$ & $\begin{array}{l}\text { Improves accessibility to } \\
\text { employment, activities etc., } \\
\text { - Maximises the availability } \\
\text { of public transport to } \\
\text { population }\end{array}$ & $\begin{array}{l}\text { Decreases } \\
\text { road transport } \\
\text { accidents and } \\
\text { their severity }\end{array}$ & \\
\hline $\begin{array}{l}\text { Lautso and } \\
\text { Toivanen } \\
\text { (1999) }\end{array}$ & $\begin{array}{l}\text { Reduces } \\
\text { congestion levels }\end{array}$ & $\begin{array}{l}\text { - } \text { Minimise consumption of natural } \\
\text { - } \quad \text { Reduces sollution }\end{array}$ & $\begin{array}{l}\text { - Meets mobility needs } \\
\text { equitably } \\
\text { - } \quad \text { Provides opportunities }\end{array}$ & 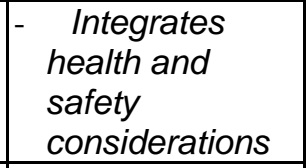 & \\
\hline Black (2000) & & $\begin{array}{l}\text { - Minimises use of finite resources } \\
\text { - Reduces atmospheric pollution }\end{array}$ & & $\begin{array}{l}\text { Minimises } \\
\text { accidents and } \\
\text { fatalities }\end{array}$ & \\
\hline $\begin{array}{l}\text { Gudmundsson } \\
\text { and Hojer } \\
\text { (1996) }\end{array}$ & & $\begin{array}{l}\text { - Safeguards natural resource } \\
\text { base within critical loads, levels } \\
\text { and usage patterns }\end{array}$ & $\begin{array}{l}\text { Maintains the option value } \\
\text { of a productive capital base } \\
\text { for future generations } \\
\text { - Improves the quality of life } \\
\text { for individuals } \\
\text { Secures an equitable } \\
\text { distribution of life quality }\end{array}$ & & \\
\hline $\begin{array}{l}\text { Croydon } \\
\text { Borough } \\
\text { Council (2004) }\end{array}$ & & 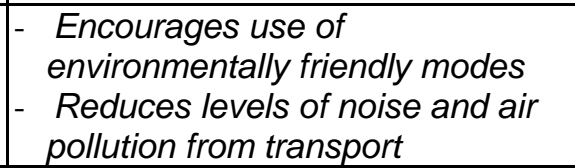 & $\begin{array}{l}\text { - Reduces dependency on } \\
\text { car travel } \\
\text { - Improves accessibility }\end{array}$ & $\begin{array}{l}\text { Minimises } \\
\text { danger and } \\
\text { perception of } \\
\text { risk. }\end{array}$ & $\begin{array}{l}\text { - Promotes economic } \\
\text { growth and planning }\end{array}$ \\
\hline
\end{tabular}

Table 1: Fit of commonly proposed sustainable transport attributes with PROSPECTS objectives 


\section{Indicators as sustainable transport assessment tools}

As with any goal, it is important that systems and methodologies exist to measure, assess and monitor progress towards sustainable transport.

Sustainable transport is a broad and complex goal however, and any assessment tool must be able to adequately provide decision makers with informative signals on the multiplicity of issues involved.

Indicators have been advanced by many authors as being appropriate tools for this purpose (see for example, Mitchell 1996, Bell and Morse 2000, Hens and De Wit 2003 , May et al 2008, etc.). The attractiveness of indicators in this context is primarily due to their ability to capture the multidimensionality of sustainable transport, break down the complex concept into small and manageable units of information and facilitate comparison, benchmarking and communication.

\subsection{The role for systematic indicator selection frameworks}

The selection of the right indicators to guide sustainable transport assessment presents two fundamental challenges. Firstly, a large number of potential sustainable transport indicators exist, and selecting a subset from this large pool can be challenging. Secondly, indicators are only abstractions of the system - designed to tell a partial story, and no indicator or set of indicators will ever perfectly represent the system. It is therefore important to select the right indicator suite that tells a good enough story.

It is likely that the indicator selection process will be improved if undertaken within the context of a systematic framework with clearly defined processes and criteria. In particular, a systematic framework could alleviate what March and Simon (1958) refer to as 'bounded rationality' and 'satisficing' tendencies by decision makers. Furthermore, a systematic framework can enhance the transparency and consistency of the indicator selection process, and improve the acceptability and credibility of the indicators selection process (Mitchell et al 1995).

\section{The ELASTIC Framework}

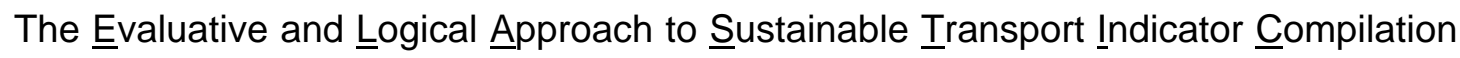
(ELASTIC) is a systematic framework for selecting a subset of indicators based on 
stakeholder judgements of their methodological strengths and relevance to key principles of sustainable transport.

A conceptual model of ELASTIC is shown graphically in Figure 1 below where the setps in the process can be clearly seen.
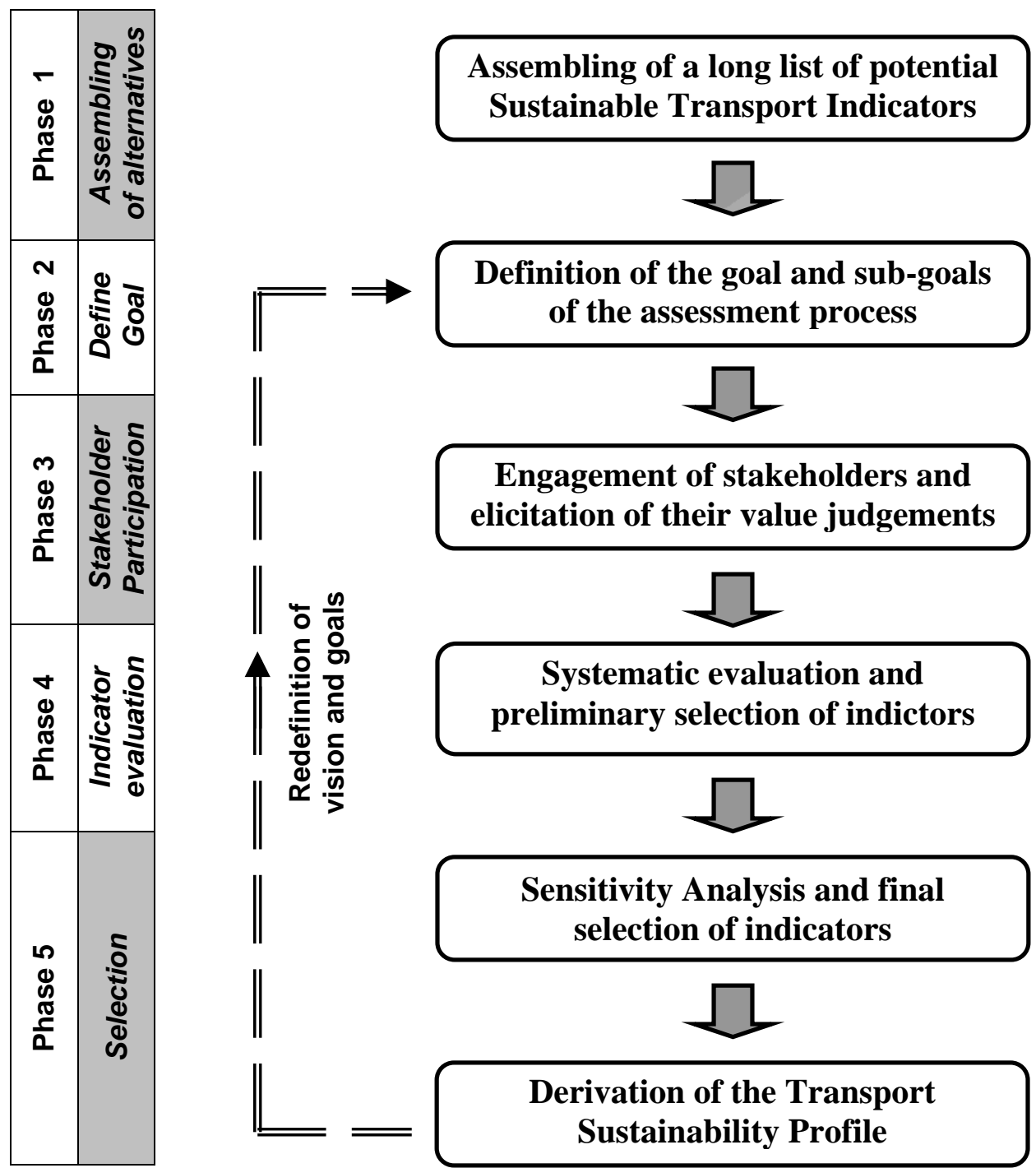

Figure 1: A conceptual model of the ELASTIC framework and processes

The output of ELASTIC is the Transport Sustainability Profile (TSP), a small unaggregated suite of context-specific sustainable transport indicators.

An application of ELASTIC is described below which provides greater insight into its inherent processes and outputs. 


\section{Application of ELASTIC to the English Regions, UK}

Sustainable transport is now the fundamental goal of transport planning in England (DfT 2007). As such, there is now an overwhelming requirement, in some cases statutory, for derivation and application of sustainable transport indicators. This makes England well suited for the application and testing of ELASTIC.

\subsection{The initial long list of indicators}

For the application of ELASTIC to the English regions, an initial long list of 233 sustainable transport indicators was identified from nine specific sources shown in Table 2 below.

\begin{tabular}{|l|l|}
\hline \multicolumn{1}{|c|}{ Source } & $\begin{array}{l}\text { Number of } \\
\text { Indicators }\end{array}$ \\
\hline Modelling for sustainable cities: The transport sector (Kupiszewska 1997) & 32 \\
\hline $\begin{array}{l}\text { Indicators for the integration of environmental concerns into transport } \\
\text { policies (OECD 1999) }\end{array}$ & 27 \\
\hline $\begin{array}{l}\text { Indicators of transport and environment integration TERM 2002 (European } \\
\text { Environmental Agency 2002) }\end{array}$ & 38 \\
\hline \begin{tabular}{l} 
Sustainable Transport Indicator Project, CST (Gilbert et al 2002) \\
\hline The 'Civilising Cities' initiative (Jones et al 2003)
\end{tabular} & 14 \\
\hline $\begin{array}{l}\text { PROSPECTS Project's Methodological Guidebook (Minken et al 2003) } \\
\text { Securing the Future (Defra 2005) }\end{array}$ & 19 \\
\hline $\begin{array}{l}\text { Local Quality of Life Counts (DETR 2000) } \\
\text { Reports - 2005 Update (DfT 2005) }\end{array}$ & 68 \\
\hline How to monitor indicators in Local Transport Plans and Annual Progress & 8 \\
\hline
\end{tabular}

Table 2: Sources and number of indicators entered into the initial long list

\subsubsection{Defining the goal and sub-goals of the indicator selection process}

Essentially, ELASTIC proceeds by evaluating the long list of indicators in order to identify a subset that maximises desirable attributes. In that regard, the overarching vision of ELASTIC is pre-defined., i.e;

Given a set $\boldsymbol{A}$ of potential sustainable transport indicators, ELASTIC seeks to identify a subset $A^{\prime}$ of $\boldsymbol{A}$, comprised of as small as possible a number of sustainable transport indicators, judged by affected stakeholders to be the most appropriate for assessing the sustainability of a given transport system. 
This overarching vision is necessarily broad as it is intended only to provide highlevel direction for the evaluation process. For greater clarity, the vision is decomposed into more interpretable sub-goals. Two specific and non-changing subgoals are prescribed in the ELASTIC methodology;

i. Maximise the methodological quality of the indicators;

ii. Maximise the relevance of indicators to the concept of sustainable transport

These sub-goals are narrower and more focussed than the overarching vision, but are still too broad to guide the evaluation of indicators. These sub-goals are therefore decomposed further below into even more precise, narrower and measurable criteria. It is against these measurable criteria that the indicators are eventually evaluated.

Two sets of measurable criteria are required in ELASTIC - one set for each of the two sub-goals. These are discussed below.

\subsubsection{Criteria for evaluating the methodological quality of indicators}

The literature is very clear about the methodological and analytical attributes that are desirable of indicators (see for example, Jackson et al 2000, Dhakal and Imura 2003, etc.).

The ELASTIC methodology draws on this body of work and has condensed the suggested desirable attributes into five key criteria, namely:

i) Measurability: A sustainable transport indicator should be capable of being measured in a theoretically sound, dependable and easily understood manner.

ii) Ease of availability: It should be possible to easily and at a reasonable cost, collect reliable data on the indicator or calculate/forecast the value of the indicator using accepted models.

iii) Speed of Availability: Data from which the indicator is derived or calculated should be regularly updated with a view to ensuring the shortest time lag between the state of affairs being measured and the indicator becoming available.

iv) Interpretability: An indicator and its calculation should yield clear, unambiguous information that is easily understood by all stakeholders

v) Transport's impact isolatable: It should be possible to isolate transport's share of the impact that the indicator is purporting to measure. 
These criteria are pre-defined in the ELASTIC process and are not intended to be changed between applications. However, and as will be discussed later, the level of importance assigned to each criterion can be varied with context to reflect local stakeholder preferences.

\subsubsection{Criteria for evaluating relevance of indicators to sustainable transport}

As discussed in section 2, five overarching objectives for sustainable transport were proposed by the PROSPECTS project, and have been found to adequately reflect the desirable attributes of sustainable transport commonly suggested in literature and practice. In this application of ELASTIC, these overarching-objectives are taken as the basis for the criteria used to evaluate the relevance of indicators to sustainable transport. Essentially, indicators were evaluated based on how well they reflected a transport system's contribution to the following:

i) Livable Streets and Neighbourhoods: A sustainable transport system should be designed and operated in a way that enhances the physical, aesthetic and special characteristics of the area. It should support community identity and positively impact social, cultural and recreational activities within the community.

ii) Protection of the Environment: A sustainable transport system should minimise natural resource consumption, any disruption of vital habitats and actively reduce transport-related emissions and wastes.

iii) Equity and Social Inclusion: A sustainable transport system should contribute to both social and spatial equity by meeting the basic mobility and accessibility needs of all social, economic and geographical groups.

iv) Health and Safety: A sustainable transport system should be designed and operated in a way that minimises hazards to health, the incidence and fear of transport-related crime, and the numbers, severity and risks of traffic accidents.

v) Support of a Vibrant and Efficient Economy: A sustainable transport system should contribute to economic growth and support market mechanisms that reflect the true social, economic and environmental costs of activities.

It should be noted however, that these criteria for assessing the relevance of indicators to sustainable transport are not pre-defined by ELASTIC. The objectives of sustainable transport are likely to differ with context, locality, time, scientific knowledge and global events (Abolina and Zilans 2002). ELASTIC therefore allows 
for sustainable transport objectives to be varied in order to better reflect the specific to the context in which the indicators are to be applied.

\subsubsection{The need to attach weightings to sub-goals and criteria}

Stakeholder participation is a key principle of sustainability. It is therefore important that both those affected by, and those who can effect sustainable transport decisions, are involved in the indicator selection process. Furthermore, stakeholders' views on the importance of the various criteria may vary depending on regional, temporal and spatial circumstances and the context in which ELASTIC is being applied.

To address these principal issues, ELASTIC requires that 'numeric weights of importance' are attached to the various sub-goals and criteria, reflecting the affected stakeholders' judgments of their importance. These weights are derived through the application of Multi-Criteria Decision Analysis (MCDA).

Given a set of alternatives, each characterised by a set of assessments for selected criteria and an interest group whose opinions regarding the selection of criteria and the assessments have to be considered, MCDA provides a systematic procedure identifying the best alternative, the best subset or to rank them (Massam 1988).

A number of MCDA techniques exist, many of which require the decision maker to directly attach weights to the alternatives. This presents a number of problems. Zeleny (1974) has argued, for example, that attempting to extract preferences by directly questioning the decision maker is an innately defective process as humans are inherently incapable of processing the relevant information about all criteria into stable weights. Furthermore, methods that directly elicit weights are unsuited for group decision making as forging some agreement among the divergent views is often impossible (Barron and Barret 1996).

One MCDA technique, the Analytic Hierarchy Process (AHP) devised by Saaty (1980), overcomes these shortcomings as weights are not assigned directly. Instead, AHP elicits subjective comparisons from the decision-maker, and then synthesises these judgements into ratio-scale weights. Notably, these individual weights can be aggregated to derive group-weights. This non-direct weighting approach enables the incorporation of data, experience and insight in a logical and methodological manner. AHP is therefore the MCDA approach specified for use in ELASTIC to derive weights of importance for the sub-goals and criteria. 


\subsection{Surveys of stakeholders and experts}

In order to obtain the necessary sub-goal and criteria weights for this application, two sets of surveys were conducted to elicit distributional judgements from two groups of relevant transport specialists, namely (i) Transport Planners at English Municipal Councils and Authorities and (ii) Transport-related Academics at English universities.

\subsubsection{Survey 1: Weighting the methodological criteria}

The first survey was conducted via a mail questionnaire and sought to obtain stakeholder judgements on the relative importance of the methodological criteria.

In order to acquire data in a way amenable for analysis using AHP, the participants were asked to make subjective pairwise comparisons of the five methodological criteria. An example of a pairwise comparison that the participants were asked to make is shown in Figure 2.

In deciding on an indicator of 'Sustainable Transport', which of the following criteria would you deem more important for indicator choice and how strongly?

Please circle the appropriate number.

Measurability 9

$8 \quad 7$

$6 \quad 5$

4 $\begin{array}{lllllllll}2 & 3 & 4 & 5 & 6 & 7 & 8 & 9\end{array}$

Figure 2: Example of a pairwise comparison that participants are required to make

Participants were requested to base their responses on the rating scale shown in Table 3 below, which is a modified version of Saaty's (1980) scale.

\begin{tabular}{|c|c|c|}
\hline $\begin{array}{l}\text { Intensity of } \\
\text { importance }\end{array}$ & Definition & Explanation \\
\hline 1 & Equal Importance & $\begin{array}{l}\text { The two criteria being compared are of equal } \\
\text { importance to choosing a sustainable transport indicator }\end{array}$ \\
\hline 3 & Moderate Importance & $\begin{array}{l}\text { Experience and judgement slightly favours one criteria } \\
\text { over another }\end{array}$ \\
\hline 5 & Strong Importance & $\begin{array}{l}\text { Experience and judgement strongly favours one criteria } \\
\text { over the other }\end{array}$ \\
\hline 7 & Very Strong Importance & A criteria is favoured very strongly over the other \\
\hline 9 & $\begin{array}{l}\text { Overwhelmingly More } \\
\text { Important }\end{array}$ & $\begin{array}{l}\text { The evidence favouring one criteria over another is of } \\
\text { the highest possible order of affirmation }\end{array}$ \\
\hline $2,4,6,8$ & $\begin{array}{l}\text { Intermediate values to } \\
\text { represent shades of } \\
\text { judgement between the five } \\
\text { basic assessments above }\end{array}$ & $\begin{array}{l}\text { There may be times when experience and judgement may } \\
\text { not render one criteria comparable to another in } \\
\text { accordance with the five scales above. Instead, a middle } \\
\text { value between two scales may be more appropriate. }\end{array}$ \\
\hline
\end{tabular}

Table 3: The scale on which respondents were requested to base their judgements 


\subsubsection{Survey 2: Weighting the sustainable transport objectives}

The second round of surveys sought to elicit stakeholder' judgements on the relative importance of the five 'objectives of sustainable transport'. An example of a pairwise comparison that the participants were asked to make in the second survey is shown below.

If you were seeking to assess the overall sustainability of a transport system based on its performance on given sustainability objectives, which of the following sustainable transport objectives would you deem more important to your decision, and how strongly so?

Please circle the appropriate number.

Livable Streets \&

Neighbourhoods

9

87

$\begin{array}{llll}6 & 5 & 4 & 3\end{array}$

2

4

$\begin{array}{llll}6 & 7 & 8 & 9\end{array}$

Health and

Safety

Figure 3: Example of a pairwise comparison given in the second survey stage

\subsubsection{Weighting the sub-goals}

In the last section of the second questionnaire, participants were asked to make a single pairwise comparison of the two ELASTIC sub-goals, i.e., 'Methodological quality' vs. 'Relevance to sustainable transport', as shown in Figure 4 below.

If you were asked to choose a sustainable transport indicator based on either its Methodological Quality or its Relevance to sustainable transport which of the two criteria would you deem more important to your selection and how strongly so?

Please circle the appropriate number.

Methodological
Quality measurability,
(i.e., mata
interpretability, data
availability, isolatability
of impacts, etc.)

Figure 4: The single pairwise comparison of sub-goals presented to participants 


\section{Results of the application of ELASTIC to England}

In the first round of surveys, a total of 57 questionnaires were sent to Transport Planners. Of these, 38 were completed, returned and used in the analysis. 64 questionnaires were sent to transport Academics, of which 34 were completed and returned. In the second round of surveys, 74 questionnaires were sent to transport planners. 39 questionnaires were returned and used in this analysis. 64 questionnaires were again circulated to Academics. 30 of these questionnaires were completed and returned.

\subsection{Weights for the criteria reflecting methodological quality}

As previously outlined, the first questionnaire required respondents to perform pairwise comparisons of ELASTIC's methodological criteria. AHP was then applied to derive weightings reflecting the preference of each respondent. These individual weightings were aggregated into (i) group weights for Transport Planners and Academics respectively; and (ii) overall weights based on judgements of all respondents. The results are shown in Table 4 below.

\begin{tabular}{|l|c|c|c|c|c|c|}
\hline \multirow{2}{*}{$\begin{array}{l}\text { Methodological } \\
\text { Criteria }\end{array}$} & \multicolumn{2}{|c|}{$\begin{array}{c}\text { Transport Planners } \\
N=38\end{array}$} & \multicolumn{2}{|c|}{$\begin{array}{c}\text { Academics } \\
N=34\end{array}$} & \multicolumn{2}{c|}{$\begin{array}{c}\text { Overall Weights } \\
N=72\end{array}$} \\
\cline { 2 - 7 } & Mean & Std Deviation & Mean & Std Deviation & Mean & Std Deviation \\
\hline Measurability & 0.22 & 0.11 & 0.22 & 0.15 & 0.22 & 0.13 \\
\hline Ease of Availability & 0.14 & 0.10 & 0.14 & 0.11 & 0.14 & 0.10 \\
\hline Speed of Availability & 0.07 & 0.08 & 0.07 & 0.03 & 0.07 & 0.06 \\
\hline Interpretability & 0.35 & 0.14 & 0.31 & 0.18 & 0.34 & 0.16 \\
\hline Isolatability & 0.21 & 0.13 & 0.26 & 0.16 & 0.23 & 0.14 \\
\hline
\end{tabular}

Table 4: Group weights and overall weights derived for the methodological criteria

A $t$-test comparison of each pair of weightings showed that there were no significant differences in the weightings that the two sample groups attached to the five methodological criteria.

\subsection{Weights for the criteria reflecting objectives of sustainable transport}

The group weights and the overall aggregated weights assigned by respondents to the criteria reflecting sustainable transport objectives are shown in Table 5 below. 


\begin{tabular}{|l|c|c|c|c|c|c|}
\hline $\begin{array}{l}\text { Objectives of } \\
\text { Sustainable } \\
\text { Transport }\end{array}$ & \multicolumn{2}{|c|}{$\begin{array}{c}\text { Transport Planners } \\
N=39\end{array}$} & \multicolumn{2}{|c|}{$\begin{array}{c}\text { Academics } \\
N=30\end{array}$} & \multicolumn{2}{c|}{$\begin{array}{c}\text { Overall Weights } \\
N=69\end{array}$} \\
\cline { 2 - 8 } & Mean & Std Deviation & Mean & Std Deviation & Mean & Std Deviation \\
\hline $\begin{array}{l}\text { Livable Streets and } \\
\text { Neighbourhoods }\end{array}$ & 0.15 & 0.08 & 0.16 & 0.10 & 0.16 & 0.09 \\
\hline $\begin{array}{l}\text { Protection of the } \\
\text { Environment }\end{array}$ & 0.17 & 0.15 & 0.24 & 0.17 & 0.20 & 0.16 \\
\hline $\begin{array}{l}\text { Equity and social } \\
\text { inclusion }\end{array}$ & 0.16 & 0.09 & 0.17 & 0.11 & 0.17 & 0.10 \\
\hline Health and Safety & 0.33 & 0.17 & 0.28 & 0.18 & 0.31 & 0.17 \\
\hline $\begin{array}{l}\text { Support of a vibrant } \\
\text { and efficient economy }\end{array}$ & 0.19 & 0.13 & 0.14 & 0.12 & 0.17 & 0.13 \\
\hline
\end{tabular}

Table 5: Group weights and overall weights for the sustainable transport objectives

A $t$-test comparison showed that there was no significant difference in the weightings that the two groups assigned to four of the five sustainable transport objectives. There was however a difference in the weight attached to the objective - Protection of the Environment, which Academics weighted higher than Transport Planners.

This may reflect the fact that the Academics surveyed were from varied transportrelated backgrounds and specialities, and may therefore be more likely to relate the concept of sustainability to the environment. This is less likely to be the case with specialist Transport Planners, who are more likely to be aware of the wider interpretation of sustainability from various government publications and guidance.

\subsection{Weights for the sub-goals}

Table 6 shows the weightings attached to the ELASTIC sub-goals.

\begin{tabular}{|l|c|c|c|c|c|c|}
\hline \multirow{2}{*}{ ELASTIC sub-goals } & \multicolumn{2}{|c|}{$\begin{array}{c}\text { Transport Planners } \\
N=39\end{array}$} & \multicolumn{2}{|c|}{$\begin{array}{c}\text { Academics } \\
N=30\end{array}$} & \multicolumn{2}{c|}{$\begin{array}{c}\text { Overall weights } \\
N=69\end{array}$} \\
\cline { 2 - 7 } & Mean & Std Deviation & Mean & Std Deviation & Mean & Std Deviation \\
\hline \hline Methodological quality & 0.49 & 0.22 & 0.47 & 0.26 & 0.48 & 0.24 \\
\hline $\begin{array}{l}\text { Relevance to sustainable } \\
\text { Transport }\end{array}$ & 0.51 & 0.22 & 0.53 & 0.26 & 0.52 & 0.24 \\
\hline
\end{tabular}

Table 6: Weights derived for the two overarching ELASTIC sub-goals

A $t$ test comparison of values showed that there were no significant differences in the weights assigned to the two sub-goals by the two groups of stakeholders. 


\subsection{The ELASTIC value tree}

Once the weightings for the sub-goals, criteria and weightings have been obtained, an ELASTIC value tree can then be derived.

The ELASTIC value tree is a graphical and hierarchical representation of the goal, sub-goals and criteria in a given sustainable transport indicator selection scenario. The competing indicators are not included in the value tree. Instead, the value tree forms the basis on which the indicators are evaluated.

The ELASTIC value tree derived for the application of the framework to the English Regions is shown in Figure 5. 


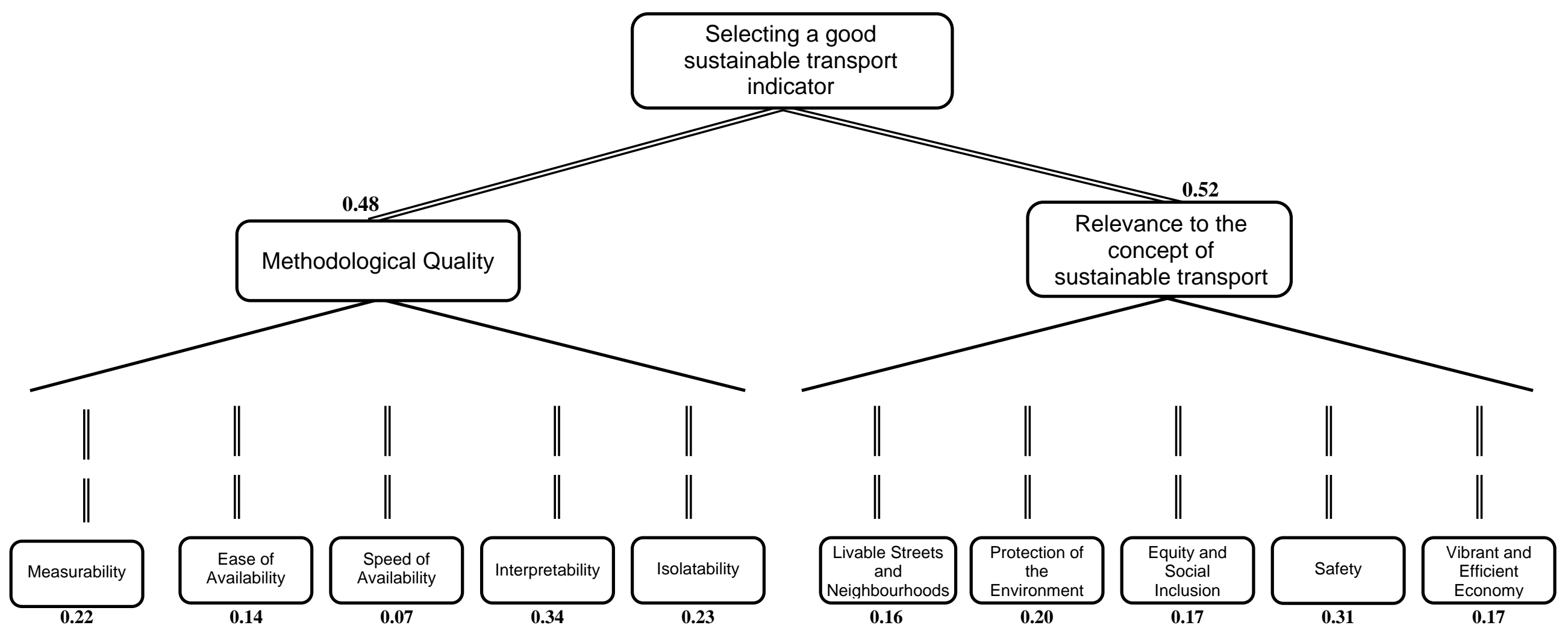

Figure 5: ELASTIC value tree for the English transport system 


\subsection{Scoring Indicator performance on criteria}

Having derived the weights for the various components of the value tree, the next stage in the ELASTIC process is the evaluation of the long list of indicators against the various sub goals and criteria. This is done by assigning an outcome score to each indicator based on its performance on each criterion.

In this application of ELASTIC, a 5-point likert scale was used as a basis for assigning outcome scores. A score of zero, i.e., 'extremely poor performance' was assigned where the indicator failed to meet any of the requirements of the criterion, whilst a score of four, i.e., 'outstanding performance' was assigned where the indicator performed exceptionally well on a criterion.

\subsection{Numerical aggregation and preliminary selection}

ELASTIC uses the Simple Additive Weighting (SAW) approach for aggregating the various weights and outcome scores to derive an overall measure of indicator performance. The basis of the SAW model is that if there are $m$ alternatives and $n$ criteria, the best alternative is the one that has the highest total weighted sum score (Triantaphyllou 2000). In ELASTIC therefore, an overall Weighted Indicator Performance Score (WIPS) is calculated for each indicator as follows;

WIPS$_{a}=\sum_{j=1}^{n} s_{j}^{a}\left(g_{k} w_{j}\right) \quad$ for all $j=1,2,3, \ldots, n$ and $k=1,2$

Where: $\quad$ WIPS $_{a}$ is the is the overall weighted performance score of indicator a;

$g_{k}$ is the importance weight of sub-goal $k$;

$w_{j}$ is the importance weight of criterion $j$;

$s_{j}^{a}$ is the normalised outcome score for indicator a on criteria $j$.

\subsection{Selection of a preliminary subset of indicators}

An initial suite of the top 20 indicators with the highest WIPS was selected for further analysis. The indicators in this initial subset are shown in Table 7. 


\begin{tabular}{|c|c|c|}
\hline Rank & Indicator & WIPS \\
\hline 1 & Motorised traffic volume & 30.59 \\
\hline 2 & Number of cycling trips & 28.87 \\
\hline 3 & Vulnerable road user accidents & 28.68 \\
\hline 4 & Local air pollutants & 27.29 \\
\hline 5 & Modal share of public transport & 26.29 \\
\hline 6 & Social/External cost of transport & 26.16 \\
\hline 7 & Quality of public transport & 26.04 \\
\hline 8 & Availability of key services locally & 25.75 \\
\hline 9 & Total number of killed or seriously injured (in road accidents) & 25.90 \\
\hline 10 & $\mathrm{CO}_{2}$ emissions from transport & 25.68 \\
\hline 11 & Public awareness of transport sustainability issues & 25.46 \\
\hline 12 & Percentage of freight transported by road & 25.45 \\
\hline 13 & Length of cycling and walking paths & 25.02 \\
\hline 14 & Access to public transport & 24.41 \\
\hline 15 & Percent of population affected by high traffic noise levels & 24.25 \\
\hline 16 & Energy consumption by the road transport sector & 24.05 \\
\hline 17 & Number of crimes committed on or while waiting for public transport & 23.93 \\
\hline 18 & Total number of road motor vehicles & 23.91 \\
\hline 19 & Transport related wastes & 23.60 \\
\hline 20 & Public participation in transport planning & 23.17 \\
\hline
\end{tabular}

Table 7: Ranking and WIPS for the preliminary twenty best performing indicators

\subsection{Sensitivity Analysis}

Sensitivity analysis is an important stage of the ELASTIC process. This stage of the framework aims is_to choose from the preliminary subset, an even smaller suite of indicators that perform consistently well even with changes to ELASTIC inputs. 
To enable the sensitivity analysis, 1000 monte carlo simulations runs were undertaken, where the sub-goals weightings, criteria weightings and outcome scores for each indicator were varied.

\subsection{Selection of a final suite of indicators}

Mean WIPS were calculated for each of the 20 indicators by taking the average of the 1000 WIPS obtained in the 1000 monte carlo simulations. The 15 indicators with the highest WIPS after sensitivity analysis are shown in Table 8.

\begin{tabular}{|l|l|c|}
\hline Rank & \multicolumn{1}{|c|}{ Indicators } & WIPS \\
\hline 1 & Motorised traffic volume & 31.57 \\
2 & Number of cycling trips & 30.60 \\
3 & Vulnerable road user accidents & 29.50 \\
5 & Local air pollutants & 28.53 \\
6 & Modal share of public transport & 27.74 \\
7 & Percentage freight transported by road & 27.63 \\
8 & Social/External costs of transport & 27.63 \\
9 & Public awareness of transport sustainability issues & 27.40 \\
10 & Availability of key services locally & 27.18 \\
11 & Quality of public transport & 27.07 \\
12 & Total number of killed or seriously injured (in road accidents) & 26.98 \\
13 & Energy consumption by the road transport sector & 26.87 \\
14 & Length of cycling and walking paths & 26.14 \\
15 & Access to public transport & 25.98 \\
\hline
\end{tabular}

Table 8: Final suite of sustainable transport indicators for the English Regions

This set of 15 indicators make up the Transport Sustainability Profile (TSP) for the English Regions, i.e., a suite of context-specific indicators selected systematically and which reflect the values and judgements of interested stakeholders.

The TSP is the final output of the ELASTIC process. 


\section{Conclusion}

Sustainability and its assessment incorporate a number of principles. Key amongst these are the need for stakeholder participation, specificity of context and a balanced approach to environmental, social and economic development.

The outputs and inherent processes of any methodology that seeks to assess sustainable transport, should therefore reflect and incorporate these principles.

The ELASTIC framework requires that the value judgements of affected stakeholders are elicited and explicitly entered into the indicator selection process. From this perspective therefore, ELASTIC meets the sustainability principle of stakeholder participation.

In addition to allowing the weights of the various sub-goals and criteria to be varied to reflect the importance afforded to them by local stakeholders, ELASTIC also allows for the sustainable transport objectives to be changed to reflect local context. Given these attributes, a strong case can be made that ELASTIC meets the sustainability principle of context specificity.

The extent to which ELASTIC provides a balanced reflection of economic, environmental and social progress is less clear cut.

Within the suite of indicators in Table 9, biases can be identified towards one or more of the sustainability dimensions. For example, indicators that address pollution and issues related to natural resource consumption, can be argued to have an 'environmental' bias. These are adequately represented in Table 9. Similarly, indicators that address issues related to safety, access and awareness can be argued to have a 'social' bias, and indeed these are adequately reflected in Table 9 as well.

However, only one indicator in Table 9, i.e. Social/External costs of Transport, can be viewed as having an 'economic' bias.

This opens the question as to whether the ELASTIC framework provides an adequate and balanced view of environmental, social and economic development. 
The framework endeavours to be stakeholder-led, and does not incorporate any rules or interventions to ensure that a particular mix or types of indicators are selected. As indicators are evaluated based on their relevance to key sustainability objectives, it is those indicators that simultaneously reflect economic, environmental and social issues that will perform best. It may be the case however, that although an indicator has implications for multiple dimensions, it may have a stronger bias towards one. The top three performing indicators in Table 9 for example, i.e., Motorised traffic volume, Number of cycling trips and Vulnerable road user accidents, all have simultaneous environmental, social and economic (efficiency) implications. However, it may be argued that Motorised traffic volume has an 'environmental' bias, whilst the latter two have a 'social' bias.

This application has shown the potential for unbalanced dimensional biases in the output of ELASTIC. Minimal bias towards one or more sustainability dimension would not adversely impact the assessment process, and could indeed be defended as reflecting the issues that stakeholders are most concerned with. However, if the bias towards one or more dimension was severe, it could result in a very narrow view of system performance which would be at odds with the fundamental premise of sustainability. Future research to minimise the risks of extreme dimensional biases may therefore strengthen the ELASTIC framework. 


\section{References}

Abolina, K., Zilans, A., 2002. Evaluation of urban sustainability in specific sectors in Latvia. Environment, Development and Sustainability, 4 (3), 299 - 314.

Barron, F, H., Barret, B. E., 1996. Decision quality using ranked attribute weights. Management Science, 42 (11), 1515 - 1523.

Bell, S., Morse, S., 2000. Sustainability Indicators. Earthscan Publications, London, UK.

Black, W. R., 2000. Socio-Economic Barriers to Sustainable Transport. Journal of Transport Geography, 8 (2), 141-147.

Croydon Borough Council, 2004. Sustainable Transport Strategy. London Borough of Croydon, Croydon, UK.

Department for Environment, Food and Rural Affairs, 2006. Securing the future - The UK Government sustainable development strategy. Defra, London

Department of the Environment, Transport, and the Regions, 1998. A new deal for transport: better for everyone. The UK Government White Paper on the Future of Transport. DETR, London, UK

Department of the Environment, Transport and the Regions, 2000. Local Quality of Life Counts: A handbook for a menu of local indicators of sustainable development. DETR, London, UK.

Department for Transport, 2004. How to monitor indicators in Local Transport Plans and Annual Progress Reports - 2004 Update. DfT, London, UK.

Department for Transport, 2007. Towards a Sustainable Transport System: Supporting Economic Growth in a Low Carbon World. DfT, London, UK.

Dhakal, S., Imura, H., 2003. Policy-based indicator systems: emerging debates and lessons. Local Environment, 8 (1), 113 - 119. 
European Commission Joint Expert Group on Transport and Environment, 2000. Implementing Sustainable Urban Transport Policies, ECMT/OECD, Paris.

European Environmental Agency, 2002. Paving the way for EU enlargement Indicators of transport and environment integration TERM 2002. Office for Official Publications of the European Communities. Luxembourg

Gilbert, R., Tanguay, H., 2000. Brief review of some relevant worldwide activity and development of an initial long-list of indicators. Centre for Sustainable Transportation, Ontario, Canada

Gilbert, R., Irwin, N., Hollingworth, B., Blais, P., Lu, H., Brescacin, N., 2002. Sustainable Transportation Performance Indicators (STPI) Project - Report on phase

3. Centre for Sustainable Transportation, Ontario, Canada.

Gudmundsson, H., Höjer, M., 1996. Sustainable development principles and their implications for transport. Ecological Economics, 19 (3), 269 - 282.

Gudmundsson, H., 2003. Making concepts matter: Sustainable mobility and indicator systems in transport policy. International Social Science Journal, 55 (2), 173 - 173.

Hens, L., De Wit, J., 2003. The development of indicators and core indicators for sustainable development: A state of the art review. International Journal of Sustainable Development, 6 (4), 436 - 459.

Jackson, L. E., Kurtz, J. C., Fisher, W. S., 2000. Evaluation guidelines for ecological indicators. U.S. Environmental Protection Agency, Office of Research and Development. North Carolina, USA.

Jones, P., Jucas, K., Whittles, M., 2003. Evaluating and implementing transport measures in a wider policy context: the 'civilising cities' initiative. Transport Policy, 10 (3), $209-221$.

Kupiszewska, D., 1997. Modelling for sustainable cities: the transport sector. Institute for Transport Studies, University of Leeds, Working Paper 521. 
Lautso, K.,Toivanen, S., 1999. SPARTACUS system for analysing urban sustainability. Transportation Research Record, 1670, 35 - 46.

Massam, B. 1988. Multi-criteria decision-making (MCDM) Techniques in Planning. In Progress and Planning, edited by D. Diamond and J. B. McLoughlin. Oxford, UK:

Pergamon Press, Vol. 30, No. 1.

May, A.D, Jarvi-Nykanen, T., Minken, H., Ramjerdi, F., Matthews, B., Monzon, A., 2001. Cities' Decision-Making requirements - PROSPECTS Deliverable 1. Institute of Transport Studies, University of Leeds, Leeds, UK

May, A.D., Page, M., Hull, A., 2008. Developing a set of decision-support tools for sustainable urban transport in the UK, Transport Policy 15 (6), 328-340

Minken, H., Jonsson, D., Shepherd, S., Järvi, T., May, A., Page, M., Pearman, A., Pfaffenbichler, P., Timms, P., Vold, A., 2003. Developing Sustainable Urban Land Use and Transport Strategies - PROSPECTS Deliverable 14. Institute of Transport Economics. Oslo, Norway.

Mitchell, G., May, A., McDonald, A., 1995. PICABUE: A methodology for the development of indicators of sustainable development. International Journal of Sustainable Development and World Ecology, 2 (2), 104 - 123.

Mitchell, G., 1996. Problems and fundamentals of sustainable development indicators. Sustainable Development, 4 (1), 1 - 11.

New Zealand Ministry of Transport 2008. New Zealand Transport Strategy.

Organisation for Economic Co-operation and Development, 1997. Towards Sustainable Transport. OECD, Paris, France.

Organisation for Economic Co-operation and Development, 1999. Indicators for the integration of environmental concerns into transport policies. OECD, Paris, France.

Shiftan, Y., Kaplan, S., Hakkert, S., 2003. Scenario building as a tool for planning a sustainable transportation system. Transportation Research D, 8 (6), 323 - 342. 
Saaty, T. L., 1980. The Analytic Hierarchy Process. McGraw-Hill, New York, USA.

Triantaphyllou, E., 2000. Multi-criteria decision making methods: A comparative study. Kluwer Academic publishers, Amsterdam, Netherlands.

United Nations, 1992. Agenda 21: An agenda for the $21^{\text {st }}$ Century. United Nations Publications, New York, USA.

Zeleny, M., 1974. A concept of compromise solutions and the method of displaced ideal. Computers \& Operational Research, 1 (3), 479 - 496. 